\title{
Comparative Intradermal Tuberculin Test in Dairy Cattle in the North of Ecuador and Risk Factors Associated with Bovine Tuberculosis
}

\author{
Freddy Proaño-Perez, Washington Benitez-Ortiz, Maritza Celi-Erazo, Lenin Ron-Garrido, \\ Ricardo Benitez-Capistros, Françoise Portaels, Leen Rigouts, and Annick Linden* \\ International Centre of Zoonosis, Central University of Ecuador, Ecuador; Mycobacteriology Unit, Institute of Tropical Medicine, \\ Antwerp, Belgium; Department of Infectious and Parasitic Diseases, Faculty of Veterinary Medicine, University of Liege, Liege, \\ Belgium; Faculty of Veterinary Medicine, Central University of Ecuador, Quito, Ecuador
}

\begin{abstract}
We studied the prevalence of bovine tuberculosis (BTB) in Mejia canton, the major dairy cattle production area in northern Ecuador. Twenty dairy herds comprising 2,022 cattle were selected. In 2007, each animal was tested using the comparative intradermal tuberculin test (CITT). In 2008, a follow-up test was performed in the same herds. The true annual incidence was $1.70 \%$, and the true prevalence was $7.41 \%$ and $7.13 \%$ in 2007 and 2008 , respectively. The prevalence was $0.27 \%$ and $0.57 \%$ in medium-sized herds in 2007 and 2008 , respectively, compared with $8.63 \%$ and $8.43 \%$ in large herds $(P<0.01)$. The number of skin test-positive cases also increased significantly with age $(P=0.03)$, contacts with other species of animals $(P<0.01)$, and introduction of new cattle $(P=0.04)$. Herd prevalence was $55 \%$ in 2007 and $65 \%$ in 2008. This study shows the lack of knowledge in cattle farmers about this zoonosis and the necessity for a national BTB control program in Ecuador.
\end{abstract}

\section{INTRODUCTION}

Bovine tuberculosis (BTB), caused by Mycobacterium bovis, is a disease that mainly affects cattle. However, humans, domestic animals, and wildlife can also be infected and have severe symptoms. ${ }^{1}$ BTB is considered by the World Organization for Animal Health (OIE) to be an important zoonotic disease of major socio-economic and public health importance, with an impact on international trade of animals and animal products.

In dairy cattle, the disease causes weight loss (36\%), decreased milk production $(13 \%)$, and lowered reproductive rate $(12 \%) .^{2}$ The costs of diagnosis and treatment of cattle and humans and the costs of correct disposal of infected animal carcases have an additional impact.

BTB is re-emerging in a number of developed countries because of environmental changes, the movement of people and animals, closer inter-species contacts, and changes in animal management. ${ }^{3}$

The prevalence and distribution of BTB in Latin America is poorly understood. The disease is officially endemic to 7 of the 34 countries in Latin America. Prevalence is high only in the Dominican Republic, 12 countries have reported as sporadic/low occurrence of $\mathrm{BTB}$, and there are no data for the remainder. ${ }^{4}$ It is estimated that $24 \%$ of the Latin American cattle population is unprotected against $\mathrm{BTB}^{5}$ and $70 \%$ of the 374 million cattle in Latin America and the Caribbean are held in areas where rates of $M$. bovis infection in cattle are $>1 \% .^{6}$ Ecuador is one of the countries with a relatively high prevalence, yet no official reports on the status of the disease are available. ${ }^{6}$ A previous study in the same region estimated an overall prevalence of $3.85 \%$ in 1,012 cattle. ${ }^{7}$ The Ecuadorian Service of Animal Health has no monitoring program, and economic losses caused by BTB have not been estimated.

The objectives of this epidemiologic study were to determine the prevalence and incidence of BTB among dairy cattle

* Address correspondence to Annick Linden, Department of Infectious and Parasitic Diseases, Faculty of Veterinary Medicine, University of Liege, Bât. B43a, Sart Tilman, Liege, Belgium. E-mail: a.linden@ulg ac.be herds in the Mejia canton, the main dairy production region in the north of Ecuador, and to describe the associated risk factors.

\section{MATERIALS AND METHODS}

Study area. The study was carried out in five of the eight districts in the Mejia canton $\left(1,459 \mathrm{~km}^{2}\right)$, in Pichincha province in northern Ecuador. This area is located between $0^{\circ} 27^{\prime} \mathrm{S}$ and $78^{\circ} 25^{\prime} \mathrm{W}$, with a mean altitude of 2,700 $\mathrm{m}$ (range, 600-4,750 m). There are in excess of 55,000 cattle in the canton, ${ }^{8}$ with $\sim 85 \%$ being dairy cattle.

Animals. Thirteen large herds (> 70 animals) and seven medium herds (between 25 and 70 animals) were included in this study, covering a total population of 2,022 cattle. Herd size criteria were arbitrarily fixed. Individual herds were selected by geographic distribution and included after agreement by the farmer. Ninety percent of the cattle tested were Holstein Friesian, the rest were Jersey, Aberdeen Angus, Normando, Brown Swiss, and cross-bred animals.

To avoid confounding effects known to occur in young animals, skin tests were performed in all cattle $>6$ months of age. Cows 1 month before and 1 month after partus were also excluded because the interpretation of comparative intradermal tuberculin test (CITT) is also difficult in these cattle. Skin tests were applied in 2007, and a follow-up study was carried out in the same herds in 2008 to evaluate the true and estimated prevalence and incidence at individual and at herd level.

CITT. The CITT was used as described in the OIE Manual of Diagnostic Tests and Vaccines for Terrestrial Animals. ${ }^{9}$ Briefly, it is based on the simultaneous use of bovine purified protein derivative AN5 strain (PPD-B) 20,000 IU/mL (Lot 06005) and avian-purified protein derivative D4 ER strain (PPD-A) 25,000 IU/mL (Lot 05001) from Symbiotics (Lyon, France).

The test was applied in the middle third of the neck of each animal; two different spots were shaved and cleaned at least $12 \mathrm{~cm}$ apart; the thickness of the skin was measured; and avian (PPD-A) and bovine (PPD-B) antigens were injected (i.e., $0.1 \mathrm{~mL}$ of PPD-B was injected in one shaved area and $0.1 \mathrm{~mL}$ of PPD-A was injected in the other shaved area). Skin 
thicknesses were measured again with calipers (Hauptner Herberholz, Germany) equipped with a spring to avoid manual pressure 72 hours after PPD injections. Measurements were always carried out by the same researcher.

The interpretation of the CITT is based on the observation that $M$. bovis-infected cattle develop a greater response to PPD-B than to PPD-A, whereas infection with M. avium or other mycobacteria induce the opposite reaction. A bovine reactor is therefore defined as an animal in which the relative increase in skin thickness at the injection site for PPD-B is at least $4 \mathrm{~mm}$ greater than the increase in skin thickness at the injection site for PDD-A. A negative reactor is identified when there is no reaction to the bovine antigen or when the difference of the skin thickness at the injection sites does not exceed $2 \mathrm{~mm}$. An inconclusive reaction was recorded if reaction to both PPD-B and PPD-A exceeded $2 \mathrm{~mm}$, but the difference between the bovine and avian reaction was $<4 \mathrm{~mm}$. To evaluate whether an animal was classified as a positive or negative avian reactor, we applied the same parameters for PPD-A interpretation.

The result was plotted on a standardized comparative cervical tuberculin graph. ${ }^{10}$ In accordance with international standards, inconclusive cases were tested again after at least 60 days to avoid the 'booster effect' of repeat PPD testing. The same scoring system was applied for this repeated testing. Animals that again had an inconclusive result were classified as "inconclusive" and therefore not considered as bovine reactors. All bovine reactors were marked using plastic earrings, and farmers/managers were advised to keep them separated from the rest of the herd to avoid the spread of the infection.

Questionnaire survey. To determine the possible risk factors related to the occurrence of BTB, each herd manager/owner was interviewed with the aid of a structured questionnaire. The questionnaire was divided into four parts comprising (1) general information about the farm, (2) livestock husbandry procedures, (3) symptoms in animals, and (4) previous diagnosis and history of the cases.

Statistical analysis. To account for the variability that is likely to exist between farms, CITT prevalence and confidence intervals (CIs) were analyzed using estimators of cluster sampling. The true prevalence and incidence estimates in both years were calculated using the Rogan and Gladen equation (1978) under a Bayesian framework,${ }^{11}$ which considered the sensitivity ( $\mathrm{Se}$ ) and specificity $(\mathrm{Sp})$ recorded for the skin test. ${ }^{12}$ This analysis enabled the determination of the Se and Sp of the CITT.

CITT results in animals were compared with data obtained per animal (lactation, age) and per farm (herd size, new cattle introduction, and contact with other species of animals). Multivariate logistic regression analysis was used to assess the relationship between risk factors and PPD-B reaction. This analysis was undertaken in Survey package $\mathrm{R}$ version 2.7.2 (Statistics Department of the University of Auckland, Auckland, New Zealand) to take into account cluster sampling. Relationships were evaluated using odds ratios (ORs) whenever possible. Statistical significance with $95 \%$ CIs was set at the 0.10 probability level assessed by $P$ values. In addition, $\chi^{2}$ tests were used to evaluate the association between PPD-A reaction response and age. We excluded all male cattle $(N=8)$ from the multivariate analysis to avoid bias related to lactation.

\section{RESULTS}

Figure 1 shows the type of farms sampled and the respective number of reactors per district in 2008. This figure also shows the location of the main city (Machachi) of the Mejia canton.

The CITT results are presented in Table 1. The overall prevalence of BTB assessed by CITT in the 20 selected herds was $7.10 \%$ (95\% CI $=0.00-14.72)$ in 2007 and $6.91 \%$ (95\% CI = $0.70-13.07)$ in 2008 in the same herds. The responses of the reactors to both PPD-A and PPD-B were $3.73 \%$ and $4.74 \%$ $(P<0.01)$, respectively. Reactions to PPD-A only were seen in $4.08 \%$ and $2.68 \%$ of the cattle in 2007 and 2008 , respectively (Table 1). In 2008, 39 new positive cases were detected by CITT, resulting in a true annual incidence of $1.70 \%(95 \%$ $\mathrm{CI}=0.04-3.13)$. The true estimated prevalence was $7.41 \%$ $(95 \% \mathrm{CI}=5.53-9.44)$ and $7.13 \%(95 \% \mathrm{CI}=4.88-9.10)$ in 2007 and 2008, respectively. Application of Rogan and Glanden's
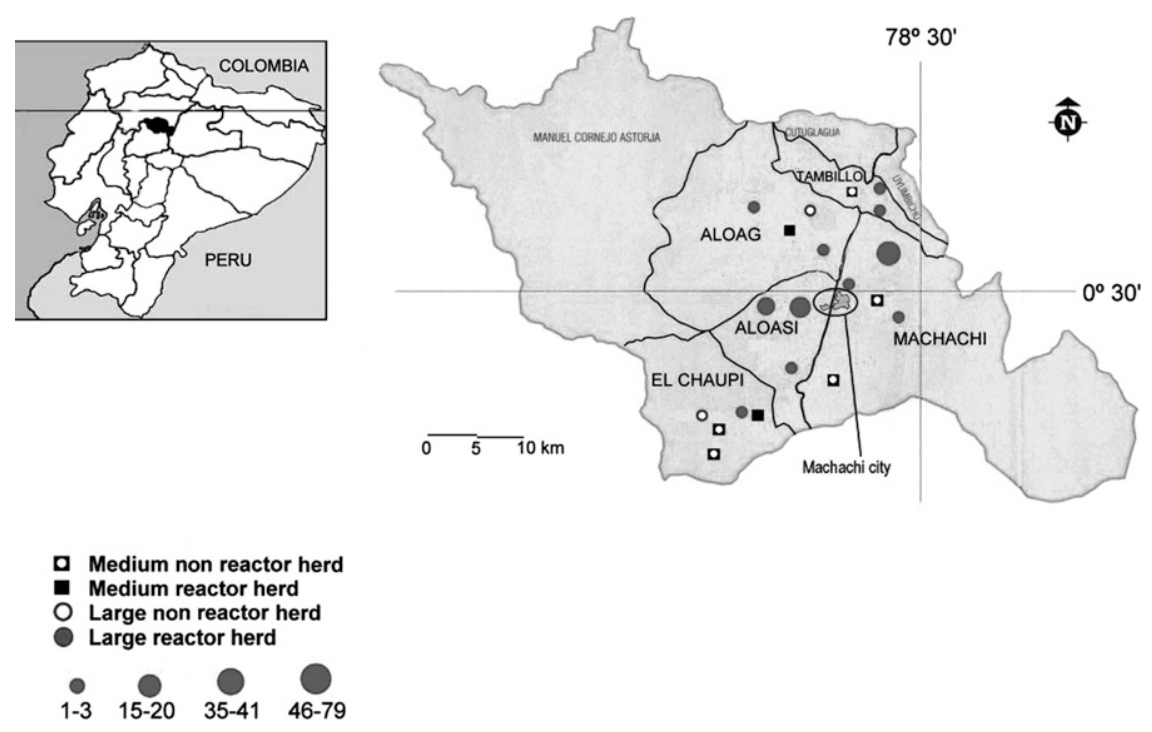

FIGURE 1. Study area with location of herds studied and estimation of bovine reactors per herd in the Mejia Canton of Ecuador in 2008. 
TABLE 1

Results of the comparative intradermal tuberculin test in relation to the herd size

\begin{tabular}{|c|c|c|c|c|c|c|c|c|c|c|c|c|c|c|c|c|c|}
\hline \multirow[b]{2}{*}{ Herd size* } & \multirow[b]{2}{*}{$\begin{array}{l}\text { No. of } \\
\text { herds }\end{array}$} & \multicolumn{7}{|c|}{ Number of bovines in 2007} & \multicolumn{9}{|c|}{ Number of bovines in 2008} \\
\hline & & Tested & $\begin{array}{l}\text { Bovine } \\
\text { reactors }\end{array}$ & Percent & $\begin{array}{c}\text { Avian } \\
\text { reactors }\end{array}$ & Percent & Inconclusive & Percent & Not read & Tested & $\begin{array}{l}\text { Bovine } \\
\text { reactors }\end{array}$ & Percent & $\begin{array}{l}\text { Avian } \\
\text { reactors }\end{array}$ & Percent & Inconclusive & Percent & Not read \\
\hline Medium & 7 & 369 & 1 & 0.27 & 15 & 4.08 & 14 & 3.79 & 1 & 354 & 2 & 0.57 & 13 & 3.75 & 17 & 4.89 & 7 \\
\hline Large & 13 & 1,653 & 142 & 8.63 & 67 & 4.08 & 61 & 3.71 & 9 & 1479 & 122 & 8.43 & 35 & 2.42 & 68 & 4.70 & 33 \\
\hline Total & 20 & 2,022 & 143 & 7.10 & 82 & 4.08 & 75 & 3.73 & 10 & 1833 & 124 & 6.91 & 48 & 2.68 & 85 & 4.74 & 40 \\
\hline
\end{tabular}

Bovine reactor is PPD-B reaction $\geq 4 \mathrm{~mm}$ compared with PPD-A; avian reactor is PPD-A reaction $\geq 4 \mathrm{~mm}$ compared with PPD-B; and inconclusive is PPD-A and PPD-B reactions $>2 \mathrm{~mm}$ and difference between PPD-B and PPD-A $<4 \mathrm{~mm}$.

$*$ Large herd $=>70$ bovines; medium herd $=$ between 25 and 70 bovines

equation showed $85 \%$ sensitivity and $99 \%$ specificity of the skin test used in this study $(95 \% \mathrm{CI}=74-94$ and $95 \% \mathrm{CI}=$ 97-99.8, respectively).

There was a clear distinction between districts with a high prevalence and districts with a low prevalence. Few cases were recorded in the districts of Aloag, Chaupi, and Tambillo against high prevalences in the Aloasi (15.36\% and $19.73 \%$ ) and Machachi (16.19\% and $12.23 \%$ ) districts (Table 2).

In 2007 , in 11 of the $20(55 \%)$ herds tested, at least one bovine reactor was found ( 1 from medium and 10 from large herds), whereas in 2008, 13 of the 20 (65\%) herds were positive ( 2 medium and 11 large herds; Figure 1 ).

Analysis of CITT results in relation to herd size showed an important difference between medium and large herds, with a BTB prevalence of $0.27 \%$ and $8.63 \%$, respectively, in 2007 and $0.57 \%$ and $8.43 \%$ in 2008 (Table 1). Herd size proved to be a significant risk factor, with large herds having a much higher prevalence of infection $(P<0.01)$.

Multivariate logistic regression analysis showed that lactating cows had a higher risk to be a bovine reactor in large than in medium herds $(\mathrm{OR}=1.75)$. A significant positive correlation between bovine PPD reaction and the age of the animals was found ( $P=0.03$; Figure 2 ; Table 3$)$. On the contrary, the avian PPD response in cattle decreased with age $(P=0.02$; data not shown). Young cattle ( $<2$ years) living in a large herd had a reduced risk compared with lactating cows from the same farm $(O R=19.48)$. Contact with other species of animals such as carnivores, small ruminants, pigs, or wildlife was also an important risk factor $(P<0.01, \mathrm{OR}=20.51)$. Introduction of new cattle was a less significant factor $(P=0.04, \mathrm{OR}=5.66)$. Cattle breed was not included in the data analysis because 90\% were Holstein Friesian (Table 3).

\section{DISCUSSION}

Prevalence and incidence of BTB. The tuberculin skin test is the internationally recognized standard method to identify infection with $M$. bovis, and it is currently the most widely applied screening test for detecting BTB in living animals. The
Se and Sp of the tuberculin skin test have been calculated to be between $77-95 \%$ and $98-99.9 \%$, respectively. ${ }^{12}$ However, the sensitivity can be affected by the potency and dose of tuberculin administered, the post-infection interval, desensitization, deliberate interference, post-partum immunosuppression, and variation in the interpretation by the observer. Contact with environmental non-tuberculous mycobacteria (NTM) or skin tuberculosis has also been documented to affect both the Se and Sp of the tuberculin test. ${ }^{13}$ In this study, we took precautions to minimize factors influencing the skin test result by carefully applying the CITT and using high-quality, well-maintained PPD products. Readings before and after injections were done by the same person, and animals $<6$ or 1 month peri-partum were excluded.

The overall apparent prevalence of BTB differed slightly between the two surveys, i.e., $7.10 \%$ and $6.91 \%$ in the same group of animals in 2007 and 2008, respectively. However, the estimated true prevalence, obtained through the Bayesian model that also considered the Se and Sp of the CITT and included all infected animals, was found to be slightly higher: $7.41 \%$ and $7.13 \%$ in 2007 and 2008, respectively. This prevalence is higher than the overall prevalence of $3.85 \%$ reported in a previous study in the same region in 2003 . $^{7}$ This difference could be attributed to the fact that the study of 2003 involved a higher number of small farms, which are known to have a lower prevalence of BTB. ${ }^{7}$

Our results might be an underestimate or overestimate of the true prevalence. We observed a strong association between the avian and the bovine PPD response $(P<0.01)$, with $3.73 \%$ and $4.74 \%$ of the PPD-B reactors also reacting to PPD-A. Because these inconclusive cases were not considered BTB positive our results may be an underestimate of the true response. On the other hand, environmental NTM could increase the relative frequency and number of false-positive skin test reactors, ${ }^{14}$ and strong avian reactions may affect the specificity of the test, which stresses the need for reviewing the interpretation of the tuberculin test in pastoral areas. ${ }^{15,16}$

In our surveys, $55 \%$ and $65 \%$ of herds were reactor herds in 2007 and 2008, respectively. It was considered a reactor herd

TABLE 2

Apparent prevalence of bovine tuberculosis by CITT in five districts of the Mejia canton

\begin{tabular}{|c|c|c|c|c|c|c|c|c|c|c|}
\hline \multirow[b]{2}{*}{ District } & \multicolumn{5}{|c|}{ Number of bovines in 2007} & \multicolumn{5}{|c|}{ Number of bovines in 2008} \\
\hline & Bovine reactors & Not read & Total & Prevalence (\%) & $95 \% \mathrm{CI}$ & Bovine reactors & Not read & Total & Prevalence (\%) & $95 \%$ CI \\
\hline Aloag & 2 & 4 & 466 & 0.43 & $0.04-0.82$ & 4 & 5 & 429 & 0.94 & $0.31-1.57$ \\
\hline Aloasi & 55 & 1 & 359 & 15.36 & $1.62-29.10$ & 60 & 7 & 311 & 19.73 & $1.05-38.81$ \\
\hline Chaupi & 4 & 1 & 352 & 1.14 & $0.00-2.79$ & 5 & 5 & 340 & 1.49 & $0.00-3.74$ \\
\hline Machachi & 80 & 1 & 495 & 16.19 & $0.00-39.95$ & 52 & 16 & 441 & 12.23 & $0.00-28.69$ \\
\hline Tambillo & 2 & 3 & 350 & 0.57 & $0.31-0.84$ & 3 & 7 & 312 & 0.98 & $0.00-2.00$ \\
\hline Total & 143 & 10 & 2,022 & 7.10 & $0.00-14.72$ & 124 & 40 & 1,833 & 6.91 & $0.7-13.07$ \\
\hline
\end{tabular}

CITT $=$ comparative intradermal tuberculin test.

$\mathrm{CI}=$ confidence interval. 


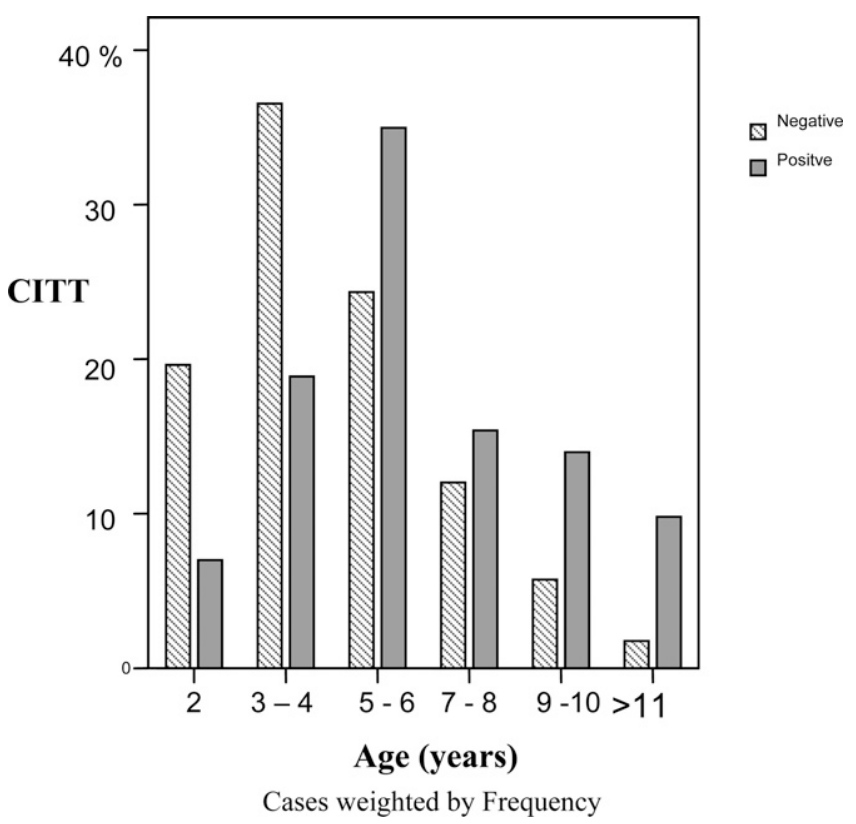

FIgURE 2. Distribution of bovine reactors to the CITT per age.

when one or more bovine reactors are found in a herd. About one half of those were large herds (10 of 20 in 2007 and 11 of 20 in 2008). In Uganda, a high herd prevalence was also noticed (46.6\%). ${ }^{17}$ As in our study, both the herd and individual prevalence was high in southern Tanzania $(51 \%$ and $13.2 \%$, respectively), ${ }^{18}$ Eritrea $(41.7 \%$ and $14.5 \%$, respectively), ${ }^{19}$ and Zambia (33\% and $7.4 \%$, respectively), ${ }^{20}$ whereas in northern Tanzania, among pastoral cattle, a moderate herd but low animal prevalence was observed $(11.8 \%$ and $0.9 \%$,

TABLE 3

Multivariable logistic regression analysis of the risk factors associated with BTB

\begin{tabular}{|c|c|c|c|c|}
\hline \multirow[b]{2}{*}{ Variables } & \multicolumn{4}{|c|}{ Logistic regression parameters } \\
\hline & Estimate & SE & $P$ value & Odds ratio $(95 \% \mathrm{CI})$ \\
\hline \multicolumn{5}{|l|}{ Lactation } \\
\hline Young cows & - & - & - & 1 \\
\hline Lactating cows & 2.97 & 0.96 & $0.01 *$ & NA \\
\hline Non-lactating cows & 2.17 & 0.61 & $<0.01 \dagger$ & NA \\
\hline \multicolumn{5}{|l|}{ Herd size } \\
\hline$\leq 70$ cows & - & - & - & 1 \\
\hline$>70$ cows & -8.34 & 1.10 & $<0.01 \ddagger$ & NA \\
\hline Age & 0.22 & 0.09 & $0.03^{*}$ & NA \\
\hline \multicolumn{5}{|l|}{$\begin{array}{l}\text { Animals introduced } \\
\text { into the herd }\end{array}$} \\
\hline No & - & - & - & 1 \\
\hline Yes & 1.73 & 0.77 & $0.04 *$ & $5.66(1.26-25.44)$ \\
\hline \multicolumn{5}{|l|}{$\begin{array}{l}\text { Contact with other } \\
\text { species }\end{array}$} \\
\hline No & - & - & - & 1 \\
\hline Yes & 3.02 & 0.60 & $<0.01 \ddagger$ & $20.51(6.38-65.92)$ \\
\hline \multicolumn{5}{|l|}{ Interaction terms } \\
\hline $\begin{array}{l}\text { Young animals } \times \\
\text { large herd }\end{array}$ & - & - & - & 1 \\
\hline $\begin{array}{l}\text { Lactating cows } \times \\
\text { medium herd }\end{array}$ & 7.78 & 1.02 & $<0.01 \ddagger$ & NA \\
\hline $\begin{array}{l}\text { Non-lactatinG cows } \times \\
\text { medium herd }\end{array}$ & -2.78 & 0.54 & $<0.01 \ddagger$ & NA \\
\hline Intercept & -10.08 & 0.89 & $<0.01 \ddagger$ & NA \\
\hline $\begin{array}{l}\text { Statistical significance code: } \\
* 0.01-0.5 \\
\dagger 0.001-0.01 . \\
+0-0.001 . \\
\text { NA = not applicable. }\end{array}$ & & & & \\
\hline
\end{tabular}

respectively). ${ }^{21}$ As in Latin America, no BTB control program is in place in most African countries.

CITT prevalence per district showed a clear variation in the geographic distribution of $M$. bovis infection with low prevalence (from $0.4 \%$ to $1.5 \%$ ) in three districts and high prevalence (from $12.2 \%$ to $19.7 \%$ ) in two districts, indicating a significant geographic variation. For this reason, we used cluster sampling to calculate the confidence intervals. No variations in the husbandry systems, breed, or climate conditions between these districts were observed. However, the difference between districts could be attributed to the location of the farms in Machachi and Aloasi districts; the majority of these farms were close to the main city of Machachi, in an area where the farm density is very high. Risk of transmission of TB is higher in where farm density is high and the vicinity of neighbors with confirmed BTB has already been mentioned as an important risk factor in a previous study. ${ }^{22}$ On the contrary, reduced farm risk for TB may be observed when large natural open lands surround the area, ${ }^{23}$ avoiding contact with cattle from other farms.

The true annual incidence calculated in this study was $1.70 \%$, which is unlikely to be influenced by removal of reactor animals, especially because infected animals were not culled. Studies to estimate the annual incidence of BTB in Latin America are scarce. In Argentina, it was calculated that on an average dairy farm without BTB control measures, one infected animal will eventually transmit the disease to 2.2 cattle per year. ${ }^{6}$ Low incidences, between $0 \%$ and $0.22 \%$, were reported in the Czech Republic, Hungary, Poland, and Slovakia between 1990 and 1999.24

Control of BTB is mainly based on the accurate detection of infected animals and removal of reactors before they become infectious for other animals in the herd. A series of tuberculin tests and subsequent culling can be applied until the herd is free of BTB. This test and cull program has allowed controlling the disease in many developed countries. ${ }^{4}$ However, in this study, on economic grounds, culling of infected cattle was impossible because Ecuador has not yet implemented a sanitation policy with official compensation for culled animals. All farmers were informed on the risks of keeping infected cattle. Culling of a number of animals including some positive reactors was done in only one large herd. The prevalence in this herd between the first and the second survey was reduced from $40.3 \%$ to $31.9 \%$. On the other hand, the recommendation to separate bovine reactors that were detected during the first survey (ear-marked) from the rest of the herd was systematically denied by the owners for the expected direct economical loss, which might have led to an overall increase of the prevalence within the herds.

We observed smaller skin reactions in older cows, although post-mortem examination showed clear macroscopic lesions. This finding requires additional research, but it limits the suggestion of Collins ${ }^{25}$ to prioritize the removal of cattle with exaggerated skin test reactions as a sanitary measure in developing countries.

Vaccination of cattle is currently not desirable because it interferes with the tuberculin skin test in the field. ${ }^{2}$ Besides, in Ecuador and other Latin American countries, in the absence of an eradication program, vaccination makes little sense.

Risk factors. This study is the first risk factor assessment of BTB in Ecuador. Similar studies have been carried out in several other countries, mainly in Africa, to understand the epidemiology of the disease at individual and at herd levels. ${ }^{17,18,26}$ 
Analysis on individual dairy cattle showed that PPD-B reactions increased significantly with age $(P=0.03)$. This was partly because older cattle, over a longer period of life, had a higher frequency of exposure to $M$. bovis than younger cattle. These data are in agreement with studies performed in Ethiopia ${ }^{27}$ and Canada, ${ }^{28}$ in which an increased incidence of BTB was observed with increasing age. However, we observed that overall skin reactions in older animals were smaller than in younger animals. This may have been because animals recently infected with $M$. bovis (i.e., 6 weeks to 3 months) show a reasonably typical and large reaction compared with infections $>6$ months. In the latter, skin tests could be less sensitive, ${ }^{29}$ or in the advanced stage of the disease, these animals may even become anergic. ${ }^{1,29}$ Risk of a positive PPD reaction can also vary with the general condition of the animals. ${ }^{20,27}$

On the other hand, PPD-A reactions decreased significantly with age $(P=0.02)$, probably because the Mycobacterium avium complex (MAC) is more prevalent in the environment than $M$. bovis, because of its higher resistance to environmental conditions. ${ }^{14}$ Young animals are in contact with these environmental mycobacteria early in life, whereas contact with $M$. bovis increases gradually with age, explaining higher PPD-A reactions at a younger age. ${ }^{14} \mathrm{~A}$ similar phenomenon is observed among children in industrialized countries with a low prevalence of TB, where M. avium and M. intracellulare are the most important species isolated in case of lymphadenitis caused by mycobacteria. ${ }^{30}$

Herd size was identified as a significant risk factor in both the 2007 and 2008 surveys, confirming the results of a previous study in the same area carried out in small, medium, and large herds. ${ }^{7}$ Likewise, in Tanzania, herds with $>50$ cattle had a significantly greater BTB prevalence $(P=0.02),{ }^{21}$ and in Canada, herds with $>80$ cattle had an increased BTB risk compared with herds with $<16$ cattle $(\mathrm{OR}=9.3) .{ }^{27}$ Similar results were obtained in Eritrea $^{19}$ and Zambia. ${ }^{20}$ In a study performed in Uganda, however, no association between herd size and positives reactions was observed. In the latter study, the association was probably masked by the effect of high between-herd interactions. ${ }^{17}$

Cattle-to-cattle transmission can be facilitated by close contact, poor ventilation systems in barns and sheds, and the herd density. ${ }^{31}$ Bacteria are shed through feces, milk, discharging lesions, saliva, and urine; likewise, transmission happens by different routes. ${ }^{32}$ In developed countries, $M$. bovis infection in cattle is mostly confined to the respiratory system; a single bacillus transported within a droplet is probably sufficient to establish infection in the bovine lung. ${ }^{33}$ Some of these transmission routes can be controlled by appropriate husbandry, ${ }^{25,34}$ and in this way, control of the disease into the herd is feasible. All farm workers were advised to apply these procedures by means of information campaigns at the end of the study.

The most dangerous spots for nose to nose or mouth to mouth contact between animals are at the salt supplementation and feeding points, ${ }^{35}$ especially in large herds with smallsized feeders. Animals under intensive farming management and confined to spaces or corrals allowing close physical contact before and during milking are more stressed. ${ }^{36}$ Such crowding was frequently observed in the study area, particularly in the largest farms.

Studies carried out in Mexico showed more TB infections in dairy than in beef cattle,,$^{37,38}$ and similarly in this survey, lactation was identified as another risk factor. Similar findings, although less significant $(P<0.05)$, have been reported from
Tanzania, with $14.6 \%$ of lactating cattle reacting to the CITT compared with $12.0 \%$ in non-lactating cows. ${ }^{18}$ In Ecuador, farmers keep old milking cows in the herd, which increases the infection risk by $M$. bovis during their life.

In developing countries, it has been reported that bovine TB infects a higher proportion of dairy breeds (Bos taurus) than indigenous zebu cattle (Bos indicus) and cross-bred beef cattle. ${ }^{1}$ Additionally, multiple logistic models showed that the presence of exotic breeds is associated with a high risk of BTB $(\mathrm{OR}=5.70)^{19}$ and compared with zebu the risk of BTB was more than twice in Holstein cattle $(\mathrm{OR}=2.32) .{ }^{27}$ In our study area, there were no Bos indicus and relation between breed and BTB infection was not performed.

Recent introduction of new animals into a herd from the market ${ }^{17}$ or from herd to herd ${ }^{17,28,39,40}$ is also a known risk factor for BTB. Our data analysis showed a significant relationship between such cattle introduction and BTB infection $(P=0.04)$. However, introduction of cattle from a different herd is not a common practice in this area, especially not in large farms.

Other risk factors mentioned in other field studies are the presence of wildlife, positive history of previous BTB within the herd, and the local herd prevalence. ${ }^{41}$ These factors were also investigated in this study. The presence of wildlife in the area was declared by the farmers, although it was never observed by us; the follow-up was limited to 2 years and because of the lack of systematic data collection before to our intervention.

The risk factors described here are not only related to cattle but can also equally contribute to the infection of $M$. bovis in humans, especially in at-risk populations in close contact with cattle and their products. In an independent study conducted in the same area (Benitez-Capristros and others, unpublished data), there was a significant association between positive skin reactions among farm workers and the presence of the disease in the herd, confirming the risk of exposure to M. bovis in those farms. Moreover, the probability for positive PPD response was almost three times higher in males $(P=0.04$; OR $=2.75)$. In developing countries, $M$. bovis is estimated to cause $2 \%$ of all human cases of TB, ${ }^{6}$ and because the prevalence in cattle seems to rise because of the lack of a national control strategy, it might have a more significant impact on human TB in the long term. BTB control strategies should be based on prevention, control, and eradication; fundamental activities concerning animal husbandry, removal of known sources of infection, early diagnosis, quarantine, movement control, and environmental hygiene must be sound. ${ }^{22}$ In further studies in this area, in vitro assays could be used in cattle such as the interferon- $\gamma$ assay. This method has a higher sensitivity and specificity compared with the skin test. ${ }^{42}$ Unfortunately, because of its high cost, it can currently only be applied for research purposes in Ecuador.

Results from this study highlight the need for a national BTB control program in Ecuador, which should be supported by sanitary policies to allow the identification of the endemic areas nationwide, establishing animal movement restrictions, culling, sanitary slaughtering, compensation strategy for culling and laboratory tests to identify the Mycobacterium species and strains involved. In addition, education of farm workers about the disease could help prevent new cases in animals and humans and help improve the use of preventive measures. 
Received April 8, 2009. Accepted for publication July 20, 2009.

Acknowledgments: The authors thank Marco Coral, Julio Ortiz, and Fabricio Anchatipan for help during the field work and all cattle owners and farm workers in the Mejia canton for assistance and willingness to participate.

Financial support: The authors gratefully acknowledge the financial support from "Commission universitaire pour le Développement" (CUD), University of Liege, Project PIC.

Authors' addresses: Freddy Proaño-Perez, International Centre for Zoonoses, Central University of Ecuador, PO Box 17-03-100, Quito, Ecuador, Tel/fax: 593-2290-4801, E-mail: fproano-ciz@ac.uce.edu.ec. Washington Benitez-Ortiz, International Centre for Zoonoses, Central University of Ecuador, PO Box 17-03-100, Quito, Ecuador, Tel/fax: 5932290-4801,E-mail: wbenitez-ciz@ac.uce.edu.ec. Maritza Celi-Erazo, International Centre for Zoonoses, Central University of Ecuador, PO Box17-03-100,Quito,Ecuador,Tel/fax:593-2290-4801,E-mail:mceli-ciz@ ac.uce.edu.ec. Lenin Ron-Garrido, International Centre for Zoonoses, Central University of Ecuador, PO Box 17-03-100, Quito, Ecuador, Tel/ fax: 593-2290-4801, E-mail: lron-ciz@ac.uce.edu.ec. Ricardo BenitezCapistros, International Centre for Zoonoses, Central University of Ecuador, PO Box 17-03-100, Quito, Ecuador, Tel/fax: 593-2290-4801. Françoise Portaels, Department of Microbiology, Mycobacteriology Unit, Institute of Tropical Medicine (ITM), 155 Nationalestraat, B-2000 Antwerp, Belgium, Tel: 32-3-2476551, E-mail: fportaels@itg.be. Leen Rigouts, Department of Microbiology, Mycobacteriology Unit, Institute of Tropical Medicine (ITM), 155 Nationalestraat, B-2000 Antwerp, Belgium, Tel: 32-3-2476551, E-mail: lrigouts@itg.be. Annick Linden, Department of Infectious and Parasitic Diseases, Faculty of Veterinary Medicine, University of Liege, Bât. B43a, Sart Tilman, Liege, Belgium, Tel: 32-4-3664051, Fax: 32-4-3664565, E-mail: a.linden@ulg.ac.be.

\section{REFERENCES}

1. Acha P, Szyfres B, 2001. Zoonoses and Communicable Diseases Common to Man and Animals. Bacterioses and Mycoses. Third edition. Washington, DC: Pan American Health Organization.

2. Suazo FM, Escalera AM, Torres RM, 2003. A review of M. bovis BCG protection against TB in cattle and other animals species. Prev Vet Med 58: 1-13.

3. Abalos P, Retamal P, 2004. Tuberculosis: ¿una zoonosis re-emergente? Rev Sci Tech 23: 583-594.

4. Cosivi O, Grange JM, Daborn CJ, Raviglione MC, Fujikura T, Cousins D, Robinson RA, Huchzermeyer HF, de Kantor I, Meslin FX, 1998. Zoonotic tuberculosis due to Mycobacterium bovis in developing countries. Emerg Infect Dis 4: 59-70.

5. Gil A, Samartino L, 2001. Zoonosis en los Sistemas de Producción Animal de las Areas Urbanas y Periurbanas de América Latina. Livestock Policy Discussion Paper No. 2. Rome: FAO.

6. de Kantor IN, Ritacco V, 2006. An update on bovine tuberculosis programmes in Latin American and Caribbean countries. Vet Microbiol 112: 111-118.

7. Proaño-Perez F, Rigouts L, Brandt J, Dorny P, Ron J, Chavez M, Rodriguez R, Fissette K, Van Aerde A, Portaels F, Benitez-Ortiz W, 2006. Preliminary observations on Mycobacterium spp. in dairy cattle in Ecuador. Am J Trop Med Hyg 75: 318-323.

8. SICA, 2000. Servicio de informática y Censo agropecuario del Ministerio de Agricultura y Ganadería del Ecuador. Tercer Censo Nacional Agropecuario. Available at: http://www.sica .gov.ec/censo/docs/nacionales/tabla6.htm. Accessed May 2, 2008.

9. Anonymous, 2008. Manual of Diagnostic Tests and Vaccines for Terrestrial Animals. Paris: International Office of Epizootic (OIE).

10. Grooms D, Molesworth J, 2000. The Comparative Cervical Tuberculin Test. Michigan State University Extension. Bovine TB Notes. Extension Buletin E-2731,New, September.Available at:http://cvm.msu.edu/extension/docs/TB/E-2731.pdf. Accessed October 10, 2008.

11. Berkvens D, Speybroeck N, Praet N, Adel A, Lesaffre E, 2006. Estimating disease prevalence in Bayesian framework using probabilistic constraints. Epidemiology 17: 145-153.

12. Monaghan ML, Doherty ML, Collins JD, Kazda JF, Quinn PJ, 1994. The tuberculin test. Vet Microbiol 40: 111-124.
13. Cooney R, Kazda J, Quinn J, Cook B, Muller K, Monaghan M, 1997. Environmental mycobacteria in Ireland as a source of non-specific sesitisation to tuberculins. Ir Vet J 41: 363-366.

14. Biet F, Boschiroli ML, Thorel MF, Guilloteau LA, 2005. Zoonotic aspects of Mycobacterium bovis and Mycobacterium aviumintracellulare complex (MAC). Vet Res 36: 411-436.

15. Oloya J, Kazwala R, Lund A, Opuda-Asibo J, Demelash B, Skjerve E, Johansen TB, Djønne B, 2007. Characterisation of mycobacteria isolated from slaughter cattle in pastoral regions of Uganda. BMC Microbiol 7: 95.

16. Shirima GM, Kazwala RR, Kambarage DM, 2003. Prevalence of bovine tuberculosis in cattle in different farming systems in the eastern zone of Tanzania. Prev Vet Med 57: 167-172.

17. Oloya J, Muma JB, Opuda-Asibo J, Djønne B, Kazwala R, Skjerve E, 2007. Risk factors for herd-level bovine-tuberculosis seropositivity in transhumant cattle in Uganda. Prev Vet Med 80: 318-329.

18. Kazwala RR, Kambarage DM, Daborn CJ, Nyange J, Jiwa SF, Sharp JM, 2001. Risk factors associated with the occurrence of bovine tuberculosis in cattle in the southern highlands of Tanzania. Vet Res Commun 25: 609-614.

19. Omer MK, Skjerve E, Woldehiwet Z, Holstad G, 2001. A crosssectional study of bovine tuberculosis in dairy farms in Asmara, Eritrea. Trop Anim Health Prod 33: 295-303.

20. Cook AJ, Tuchili LM, Buve A, Foster SD, Godfrey-Fausett P, Pandey GS, McAdam KP, 1996. Human and bovine tuberculosis in the Monze District of Zambia-a cross-sectional study. Br Vet J 152: 37-46.

21. Cleaveland S, Shaw DJ, Mfinanga SG, Shirima G, Kazwala RR, Eblate E, Sharp M,2007. Mycobacterium bovis in rural Tanzania: risk factors for infection in human and cattle populations. Tuberculosis (Edinb) 87: 30-43.

22. Denny GO, Wilesmith JW, 1999. Bovine tuberculosis in northern Ireland: a case-control study of herd risk factors. Vet Rec 144: 305-310.

23. Kaneene JB, Bruning-Fann CS, Granger LM, Miller R, PorterSpalding BA, 2002. Environmental and farm management factors associated with tuberculosis on cattle farms in northeastern Michigan. J Am Vet Med Assoc 221: 837-842.

24. Pavlik I, Yayo Ayele W, Parmova I, Melicharek I, Hanzlikova M, Kormendy B, Nagy G, Cvetnic Z, Ocepek M, Fejzic N, Lipiec M, 2002. Incidence of bovine tuberculosis in cattle in seven central European countries during the years 1990-1999. Vet. Med Czech 47: $45-51$.

25. Collins JD, 2006. Tuberculosis in cattle: strategic planning for the future. Vet Microbiol 112: 369-381.

26. Munyeme M, Muma JB, Skjerve E, Nambota AM, Phiri IG, Samui KL, Dorny P, Tryland M, 2008. Risk factors associated with bovine tuberculosis in traditional cattle of the livestock/wildlife interface areas in the Kafue basin of Zambia. Prev Vet Med 85: 317-328.

27. Ameni G, Aseffa A, Engers H, Young D, Gordon S, Hewinson G, Vordemeier M, 2007. High prevalence and increased severity of pathology of bovine tuberculosis in Holsteins compared to zebu breeds under field cattle husbandry in central Ethiopia. Clin Vaccine Immunol 14: 1356-1361.

28. Munroe FA, Dohoo IR, McNab WB, Spangler L, 1999. Risk factors for the between-herd spread of Mycobacterium bovis in Canadian cattle and cervids between 1985 and 1994. Prev Vet Med 41: 119-133.

29. Cousins DV, Huchzermeyer HFKA, Griffin JFT, Bruckner GK, Van Rensburg IBJ, Kriek NPJ, 2004. Tuberculosis. Coetzer JAW, Tustin RC, eds. Infectious Diseases of Livestock. Second edition. New York: Oxford University Press, 1973-1989.

30. Lindeboom JA, Kuijper EJ, Prins JM, Bruijnesteijn van Coppenraet ES, Lindeboom R, 2006. Tuberculin skin testing is useful in the screening for nontuberculous mycobacterial cervicofacial lymphadenitis in children. Clin Infect Dis 43: 1547-1551.

31. Goodchild AV, Clifton-Hadley RS, 2001. Cattle-to-cattle transmission of Mycobacterium bovis. Tuberculosis (Edinb) 81: 23-41.

32. Neill SD, O'Brien JJ, Hanna J, 1991. A mathematical model for Mycobacterium bovis excretion from tuberculous cattle. Vet Microbiol 28: 103-109.

33. Menzies FD, Neill SD, 2000. Cattle-to-cattle transmission of bovine tuberculosis. Vet J 160: 92-106. 
34. Phillips CJ,Foster CR, Morris PA, Teverson R, 2003. The transmission of Mycobacterium bovis infection to cattle. Res Vet Sci 74: 1-15.

35. Ayele WY, Neill SD, Zinsstag J, Weiss MG, Pavlik I, 2004. Bovine tuberculosis: an old disease but a new threat to Africa. Int $J$ Tuberc Lung Dis 8: 924-937.

36. Parra A, Larrasa J, García A, Alonso JM, de Mendoza JH, 2005. Molecular epidemiology of bovine tuberculosis in wild animals in Spain: a first approach to risk factor analysis. Vet Microbiol 110: $293-300$

37. Brown WH, Hernández de Anda J, 1998. Tuberculosis in adult beef cattle of Mexican origin shipped direct-to-slaughter into Texas. J Am Vet Med Assoc 212: 557-559.

38. Milian-Suazo F, Salman MD, Ramirez C, Payeur JB, Rhyan JC, Santillan M,2000. Identification of tuberculosis in cattle slaughtered in Mexico. Am J Vet Res 61: 86-89.
39. Marangon S, Martini M, Dalla Pozza M, Neto F, 1998. A case-control study on bovine tuberculosis in the Veneto Region (Italy). Prev Vet Med 34: 87-95.

40. Gopal R, Goodchild A, Hewinson G, de la Rua Domenech R, Clifton-Hadley R, 2006. Introduction of bovine tuberculosis to north-east England by bought-in cattle. Vet Rec 159: 265-271.

41. Olea-Popelka FJ, White PW, Collins JD, O'Keeffe J, Kelton DF, Martin SW, 2004. Breakdown severity during a bovine tuberculosis episode as a predictor of future herd breakdowns in Ireland. Prev Vet Med 63: 163-172.

42. Gormley E, Doyle MB, Fitzsimons T, McGill K, Collins JD, 2006. Diagnosis of Mycobacterium bovis infection in cattle by use of the gamma-interferon (Bovigam1) assay. Vet Microbiol 112: $171-179$. 